\title{
Transient myocardial ischaemia after acute myocardial infarction does not induce ventricular arrhythmias
}

Peter Currie, Stephen Saltissi

\begin{abstract}
Objective-To see whether transient myocardial ischaemia on ambulatory monitoring after myocardial infarction is associated with ventricular arrhythmias.

Design-A prospective study.

Setting-The coronary care unit, general medical wards, and cardiorespiratory department of a major teaching hospital.
\end{abstract}

Patients-203 consecutive patients without specific exclusion criteria admitted with acute myocardial infarction.

Interventions-24 hour ambulatory electrocardiographic monitoring for ventricular arrhythmias and ST depression both early (mean 6.3 days after infarction, $n=201$ ) and late (mean 38 days, $n$ = 177).

Main outcome measures-Episodes of myocardial ischaemia were identified during ambulatory monitoring by transient ST depression of $\geqslant 1.0 \mathrm{~mm}$ lasting for $\geqslant 30 \mathrm{~s}$. Ventricular arrhythmias were single extrasystoles, couplets, or ventricular tachycardia.

Results-All ventricular arrhythmias were significantly more frequent in late than early monitoring. The arrhythmias included couplets (in 83/174 (48\%) $v$ $49 / 200(25 \%)$ of patients, $p=0.0000028$ ) and ventricular tachycardia (29/174 (17\%) $v 15 / 199(8 \%), p=0.0064)$. Patients with ST depression (29 early; 56 late), compared with those without ischaemia, did not experience a significant increase in single extrasystoles, couplets $(31 \% v$ $23 \%$ early; $47 \% v 48 \%$ late), or ventricular tachycardia (3\% v 8\% early; $18 \% v$ $16 \%$ late). Even patients with frequent ( $\geqslant 3$ episodes), and deep ( $\geqslant 1.5 \mathrm{~mm}$ ) or prolonged ( $\geqslant 20 \mathrm{~min}$ ) ST depression had no increase in arrhythmias.

Conclusions-Ventricular arrhythmias after myocardial infarction are not associated with transient myocardial ischaemia during daily activities. This study does not support the belief that to abolish silent ischaemia would reduce the incidence of sudden death due to uncontrollable ventricular arrhythmias after myocardial infarction.

(Br Heart f 1993;69:303-307)

Although silent myocardial ischaemia has been shown in patients surviving out of hospital ventricular fibrillation ${ }^{1}$ and myocardial ischaemia has been implicated in patients dying with arrhythmias during ambulatory monitoring ${ }^{2}$ it remains uncertain whether transient myocardial ischaemia is arrhythmogenic or is simply an indicator of severe coronary artery disease with its attendant risk of sudden coronary occlusion. Although Deanfield et al noted short runs of ventricular tachycardia in association with silent and symptomatic episodes of ischaemia ${ }^{3}$, other workers found no ventricular tachycardia associated with 446 episodes of silent ischaemia. ${ }^{4}$ Quyyumi et al found ventricular tachycardia (non-sustained) in only $8.1 \%$ of patients with coronary artery disease and in only $2 \cdot 7 \%$ could the arrhythmia be related to ST segment changes. ${ }^{5}$ Ventricular tachycardia or fibrillation were noted by Maseri et al during transient ischaemic episodes in 28 patients with angina at rest but $89 \%$ of these episodes were accompanied by ST elevation, implying relatively severe ischaemia. ${ }^{6}$

We have studied the relations of ventricular arrhythmias to transient ischaemic ST depression and prospectively evaluated the prevalence, characteristics, and implications of myocardial ischaemia detected on ambulatory monitoring after recent myocardial infarction.

\section{Patients and methods}

The patients in this study were admitted to the Royal Liverpool Hospital between September 1987 and December 1988. All patients with definite acute myocardial infarction ${ }^{7}$ were eligible for the study provided they did not have cardiogenic shock, valvar heart disease, left ventricular hypertrophy, electrocardiographic conduction defect, other serious diseases, or a current prescription for digitalis. Of 358 patients screened 14 refused consent, 24 died shortly after admission, and eight patients had been recruited previously. A further 109 patients were excluded for the reasons listed above. We therefore performed ambulatory monitoring in 203 patients with myocardial infarction (152 men, 51 women of mean age 58 (range 34-76) years).

Ninety three patients $(46 \%)$ had an anterior or lateral infarct and $110(54 \%)$ an inferior or posterior infarct. In 47 patients $(23 \%)$ there was a non $Q$ wave infarct, 36 patients $(18 \%)$ received thrombolytic treatment, and $46(23 \%)$ had had a previous infarct.

AMBULATORY MONITORING

Ambulatory monitoring was performed both early (before discharge) and late (four to eight 
weeks after admission) with the Oxford Medilog 4000-II (real time ST segment analysis) for up to 24 hours. This equipment has previously been validated at rest and on exercise $^{8}$ and the CM5 lead that was predominantly used $(92 \%$ of the early and $85 \%$ of the late monitoring) is highly sensitive for detecting ischaemia. ${ }^{9}$

Before each recording, patients underwent postural screening manoeuvres and ST segment shift with posture was taken into account in the analysis. ${ }^{10}$

\section{ST segment analysis}

The method of ST segment analysis has been described already but briefly. ${ }^{10}$ The magnetic cassette tapes were replayed in the Oxford 4500 system to produce an ST segment trend. All episodes of ST depression detected on the ST trend were validated on electrocardiographic strips printed at each point of interest (fig 1). Transient myocardial ischaemia was defined as at least 30 seconds of $1.0 \mathrm{~mm}$ or more planar and downsloping ST depression, measured at $80 \mathrm{~ms}$ after the J point. ${ }^{11}$ If, however, there was baseline ST depression of $0.5 \mathrm{~mm}$ or more when supine then an additional $1.0 \mathrm{~mm}$ ST depression was required for significance. Furthermore if during any postural manoeuvre there was $0.5 \mathrm{~mm}$ or more additional ST depression compared with the level when supine then the maximum ST depression during such manoeuvres was used as the baseline. The maximum ST depression and the duration of each ischaemic episode were recorded.

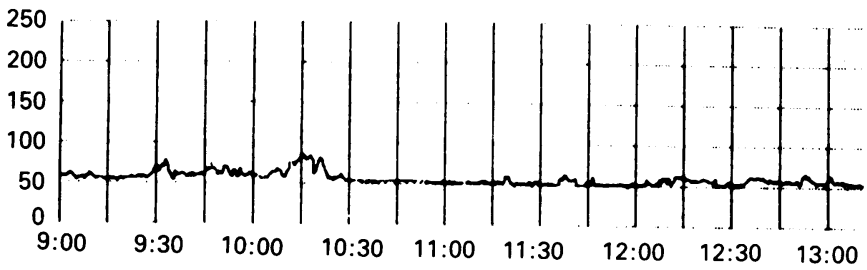

ST level ( $\mathrm{mm})$

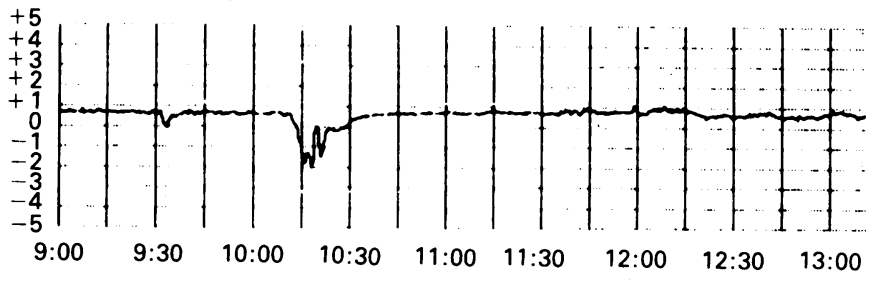

B

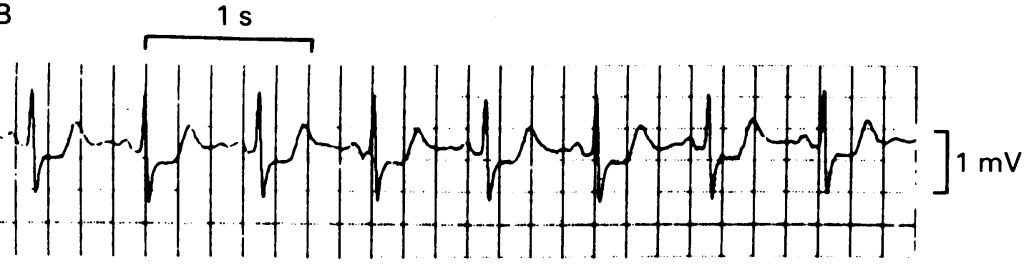

Figure 1 Detection of ischaemic ST depression by the ST trend of the Oxford Medilog 4000-II. (A) The ST trend detects an episode of ST depression associated with an increase in heart rate. (B) An electrocardiographic strip printed at 10.17 am during the episode of $S T$ trend depression validates the episode as ischaemic.
Detection of arrhythmias

Arrhythmias during ambulatory monitoring were detected by examining the automatic arrhythmia summary (produced by the Oxford Medilog system), which included the total number of single ventricular extrasystoles, episodes of ventricular tachycardia (three or more successive ventricular extrasystoles during which two $R R$ intervals exceeded 110 beats $/ \mathrm{min}$ ), coupled ventricular extrasystoles, and episodes of ventricular bigeminal or trigeminal rhythm. The accuracy of the summary was validated in 15 patients by comparison with a fully disclosed electrocardiogram (fig 2). Compared with hand counted ventricular extrasystoles the summary detected $21 \%$ more extrasystoles, but the total extrasystoles detected by the two methods were almost always of a similar order-Spearman rank order correlation coefficient of $0.96(p<0.001)$. The arrhythmia summary was $100 \%$ sensitive and $100 \%$ specific for identifying the patients with couplets $(n=4)$ and ventricular tachycardia $(n=1)$ but failed to detect the only episode of ventricular bigeminal rhythm. The summary had acceptable accuracy as a screening test, but any arrhythmias indicated by the summary during the study were also validated by checking the fully disclosed electrocardiogram.

The frequency of arrhythmias was compared directly in patients with (fig 3) and without ST depression on early or late ambulatory monitoring and during recording periods with or without ST depression.

GATED BLOOD POOL VENTRICULOGRAPHY

Left ventricular ejection fraction was assessed in 134 patients by gated blood pool ventriculography at 69 (28) (mean (SD); range 17-152) days after infarction with in vivo red blood cell labelling with $550 \mathrm{MBq}$ of intravenous ${ }^{99 \mathrm{~m} T c}$ pertechnetate. Scanning was performed in the $45^{\circ}$ left anterior oblique position with a $15^{\circ}$ caudal tilt. Data were collected by a Nuclear Diagnostics computer ( 24 time intervals for each cardiac cycle up to a total of 10 million counts) and analysed with standard software.

\section{STATISTICAL ANALYSIS}

The frequency of ventricular arrhythmias in patient groups was compared with the $\chi^{2}$ test incorporating the continuity equation where appropriate. Non-parametric data such as frequency of ventricular extrasystoles an hour were compared by the Wilcoxon rank sum test.

Approval was obtained from the local ethics committee before the study began. Patients gave informed consent.

\section{Results}

PREVALENCE OF ISCHAEMIA ON AMBULATORY MONITORING

The detailed characteristics of transient ambulatory myocardial ischaemia and its relation to myocardial ischaemia detected by 


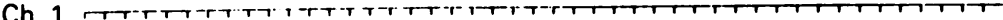

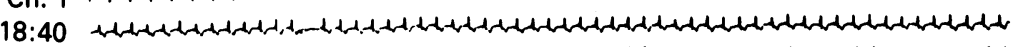

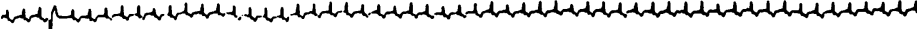

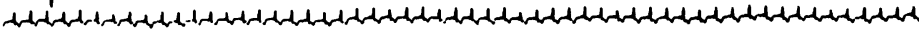

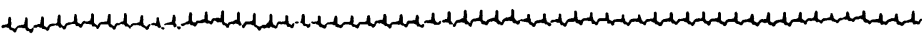

$18: 43$

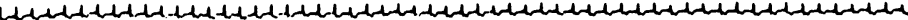

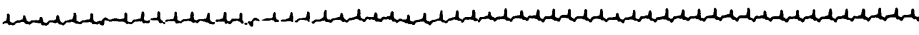

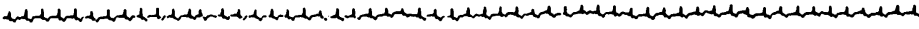

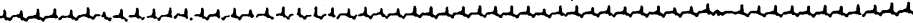

$18: 46$

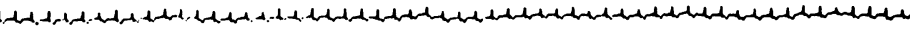

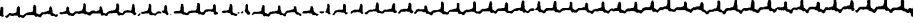

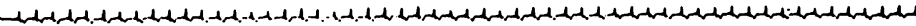

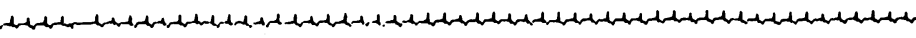

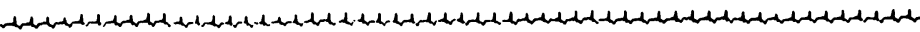
it

18:52

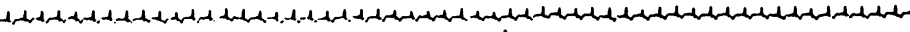

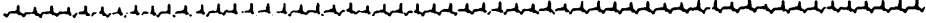

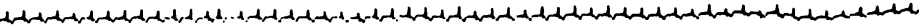

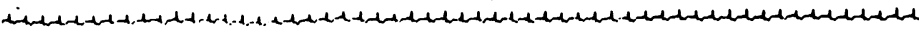

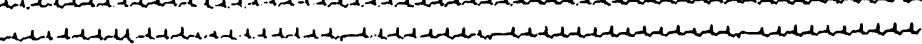

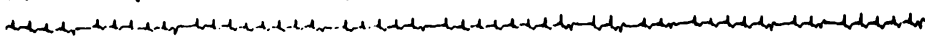

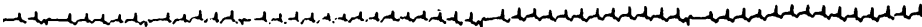

18:58

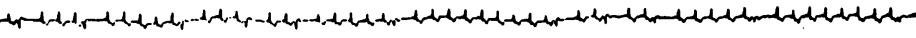

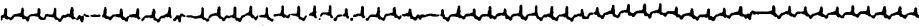

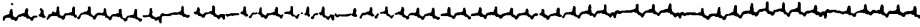

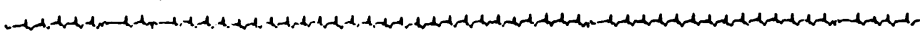

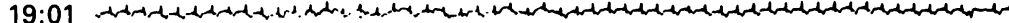

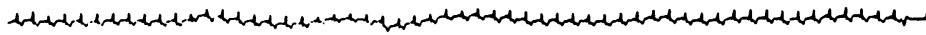

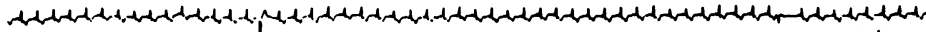

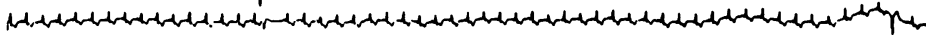

19:04

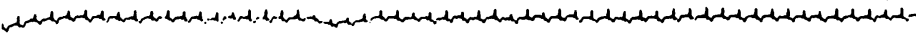

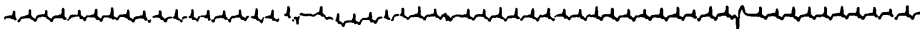

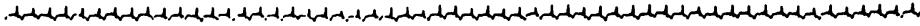

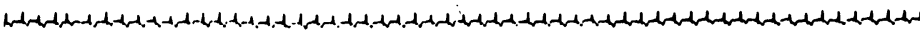

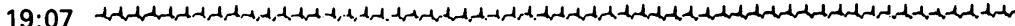
1 1.

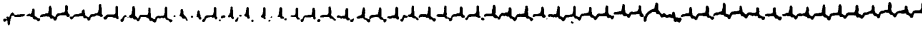

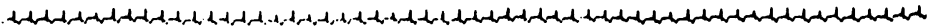

Figure 2 Fully disclosed electrocardiogram of the Oxford Medilog 4000-II printed on a small scale (30 min/page), which allows ventricular arrhythmias to be detected and ventricular extrasystoles to be counted.

exercise testing in this population have been previously described. ${ }^{1012}$ Briefly, 107 episodes of transient ST depression occurred in $29 / 201$ patients $(14 \%)$ in early monitoring but ST depression was considerably more frequent later (280 episodes in 56/177 patients; $32 \%)$. These ischaemic episodes were symptom free both early (85\% episodes) and late $(94 \%)$.

PREVALENCE OF VENTRICULAR ARRHYTHMIAS All ventricular arrhythmias including single ventricular extrasystoles, ventricular bigemini or trigemini, coupled extrasystoles, and ventricular tachycardia were much more common in late compared with early ambulatory monitoring (table 1). Moreover, in patients undergoing both early and late monitoring while on no antianginal drugs, ventricular arrhythmias were still much commoner on late ambulatory monitoring. The percentage of patients showing ventricular bigemini or trigemini in early monitoring was $36 \% v 5 \%$ in late and showing couplets $55 \% v 21 \%$.

Patients with a higher maximum heart rate seemed to have a higher incidence of ventricular extrasystoles. Thus more patients with a maximum heart rate of at least 100 beats/min had a mean of 10 or more ventricular extrasystoles an hour (24/119 (20\%) in early monitoring and 58/141 (41\%) in late) compared with those with a maximum of 99 beats/min or less $(3 / 67(4 \%)$ early and $6 / 23$ $(26 \%)$ late). The increased prevalence, however, of ventricular extrasystoles in late compared with early monitoring was clearly apparent regardless of maximum heart rate.

\section{VENTRICULAR ARRHYTHMIAS AND LEFT \\ VENTRICULAR FUNCTION}

The mean (SEH) number of ventricular extrasystoles tended to be commoner in patients with poor $(<50 \%)$ compared with good $(\geqslant 50 \%)$ left ventricular ejection fraction both on early (low 12.0 (6.9) $v$ high 3.3 $(1.0)$ hour $\mathrm{p}=0.13)$ and late (low $33.2(9.4)$ $v$ high $24.7(6.7), \mathrm{p}=0.017)$ ambulatory monitoring. Ventricular couplets, bigemini or trigemini, and ventricular tachycardia were also commoner in patients with a poor ejection fraction.

\section{VENTRICULAR ARRHYTHMIAS AND}

MYOCARDIAL ISCHAEMIA

There was no association between the presence of ischaemic ST depression and the frequency of ventricular arrhythmias during either early or late monitoring (table 2). When only data from patients with good or poor left ventricular function were analysed there was still no significant difference in the frequency of ventricular arrhythmias in patients with ST depression. Even patients with frequent ambulatory ST depression ( $>$ three episodes $/ 24$ hours), deep ( $>1.5 \mathrm{~mm}$ ), or prolonged ( $>20 \mathrm{~min}$ duration $/ 24 \mathrm{~h}$ ) experienced no increase in the frequency of ventricular extrasystoles, bigemini or trigemini, couplets, or ventricular tachycardia compared with patients with absent or less pronounced ST depression. Patients with considerable ambulatory ST depression had
Figure 3 The Oxford Medilog 4000-II records the electrocardiogram in two channels (although $S T$ segment analysis is performed in a single channel) to show a run of ventricular trigeminy occurring during an episode of ischaemic ST depression.

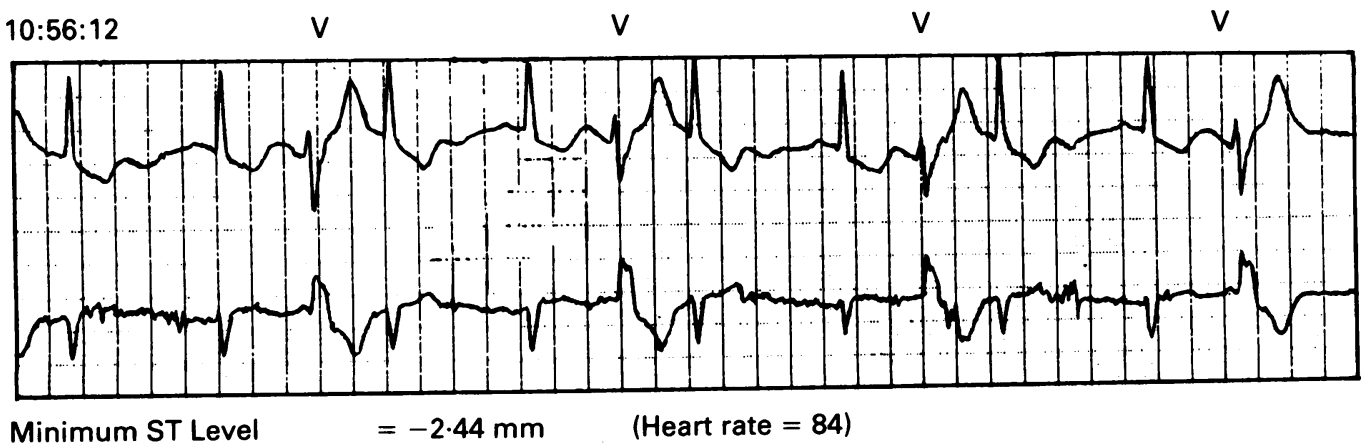


Table 1 Prevalence of ventricular arrhythmias on early and late ambulatory monitoring after myocardial infarction

\begin{tabular}{|c|c|c|c|}
\hline & $\begin{array}{l}\text { Early } \\
\text { (6 days) }\end{array}$ & $\begin{array}{l}\text { Late } \\
\text { ( } 38 \text { days) }\end{array}$ & p.Value \\
\hline \multicolumn{4}{|l|}{ Ventricular extrasystoles (single): } \\
\hline No/h (mean (SEM)) & $10 \cdot 4(3 \cdot 2)$ & $34 \cdot 2(5 \cdot 5)$ & 0.05 \\
\hline$\geqslant 10 / h$ & $30 / 200(15 \%)$ & $73 / 175(42 \%)$ & $<0.0001$ \\
\hline Bigemini or trigemini & $20 / 200(10 \%)$ & $52 / 174(30 \%)$ & $<0.0001$ \\
\hline Ventricular couplets & $49 / 200(25 \%)$ & $83 / 174(48 \%)$ & $<0.0001$ \\
\hline Ventricular tachyçardia ${ }^{\star}$ & $15 / 199(8 \%)$ & $29 / 174(17 \%)$ & 0.006 \\
\hline
\end{tabular}

${ }^{\star}$ At least three consecutive ventricular extrasystoles with a heart rate of at least 110 beats $/ \mathrm{min}$.

Table 2 Ventricular arrhythmias in patients with or without ST depression on early and late ambulatory monitoring after myocardial infarction

\begin{tabular}{|c|c|c|c|}
\hline & \multicolumn{2}{|l|}{ ST depression } & \multirow[b]{2}{*}{$p$ Value } \\
\hline & Present & Absent & \\
\hline \multicolumn{4}{|l|}{ Early monitoring (6 days): } \\
\hline $\mathrm{No} / \mathrm{h}($ mean $(\mathrm{SEM}))$ & $19 \cdot 5(7 \cdot 7)$ & $13 \cdot 6(4 \cdot 1)$ & \\
\hline$\geqslant 10 / \mathrm{h}$ & $7 / 29(24 \%)$ & $23 / 171(13 \%)$ & $0 \cdot 45$ \\
\hline Bigemini or trigemini & $6 / 29(21 \%)$ & $14 / 171(8 \%)$ & $0 \cdot 16$ \\
\hline Ventricular couplets & $9 / 29(31 \%)$ & $40 / 171(23 \%)$ & \\
\hline Ventricular tachycardia ${ }^{\star}$ & $1 / 29(3 \%)$ & $14 / 170(8 \%)$ & \\
\hline \multicolumn{4}{|c|}{$\begin{array}{l}\text { Late monitoring ( } 38 \text { days): } \\
\text { Ventricular extrasystoles (single): }\end{array}$} \\
\hline $\begin{array}{l}\text { No/h }(\text { mean }(\mathrm{SEM})) \\
\geqslant 10 / \mathrm{h}\end{array}$ & $\begin{array}{l}34 \cdot 5(9 \cdot 3) \\
22 / 56(39 \%)\end{array}$ & $\begin{array}{l}33 \cdot 7(6 \cdot 8) \\
51 / 119(43 \%)\end{array}$ & \\
\hline Bigemini or trigemini & $16 / 55(29 \%)$ & $36 / 119(30 \%)$ & \\
\hline Ventricular couplets & $26 / 55(47 \%)$ & $57 / 119(48 \%)$ & \\
\hline Ventricular tachycardia & $10 / 55(18 \%)$ & $19 / 119(16 \%)$ & \\
\hline
\end{tabular}

no increase in arrhythmias whether they had good or poor left ventricular function.

In 10 patients with ST depression on ambulatory monitoring the frequency of arrhythmias in periods with and without ischaemia was examined. During the recordings there was a total of 4.85 hours of significant ST depression (27 episodes) and 233 hours without ST depression. The mean (SEM) incidence of single ventricular extrasystoles an hour was similar during periods with (39.6 (26.4)/hour) and without (39.0 (12.6)) ischaemic ST depression. Also the hourly incidence of couplets was similar $(0.41 v 0.47)$.

In the five patients who had both ventricular arrhythmias and the most frequent late ST depression (those having $24,17,17,14$, and 10 episodes each/recording), the incidence of arrhythmias was evaluated in all hours containing an ischaemic episode. There were a total of 114 full recording hours of which 61 (54\%) contained at least one episode of ST depression. In this analysis the rate of ventricular extrasystoles an hour was not significantly $(\mathrm{p}=0.32)$ higher during hours with ST depression (18.1 (2.9) v 15.7 (3.0)/hour, mean (SEM)). Moreover the incidence of couplets $(11 / 61$ (18\%) v 10/53 (19\%)), bigemini or trigemini $(3 / 61(5 \%) v 2 / 53$ $(4 \%))$, ventricular tachycardia $(0 / 61(0 \%) v$ $1 / 53(2 \%)$ ), or 10 or more ventricular extrasystoles in the hour $(30 / 61(49 \%) v$ $21 / 53(40 \%)$ were similar during ischaemic and non-ischaemic hours.

\section{Discussion}

Symptom free coronary artery disease has been linked with ventricular arrhythmias and sudden death, ${ }^{1}$ but whether short lived episodes of ST depression are an important cause of life threatening ventricular arrhythmias has not been proved. This study has provided circumstantial evidence that silent transient myocardial ischaemia is probably not an important arrhythmogenic factor in patients convalescing after acute myocardial infarction. Thus ventricular arrhythmias overall were no commoner in patients who had ST depression on ambulatory monitoring either before discharge or at four to eight weeks after myocardial infarction, even when an analysis was performed on patients with more pronounced ST depression.

In this study, the well recognised relation between impaired left ventricular function and ventricular arrhythmias was confirmed. To eliminate the effect of this strong influence, the analysis was repeated in the subgroup with left ventricular ejection fraction of $\geqslant 50 \%$, when again ST depression was not associated with ventricular arrhythmias. Further, when periods of ischaemia (or hours containing ischaemia) were compared with periods (or hours) without ischaemia there was still no increase in ventricular extrasystoles (including solitary, couplets, or ventricular tachycardia) associated with the ischaemia.

These results are in keeping with most previous studies in other groups of patients with coronary artery disease, in whom ventricular arrhythmias (frequent extrasystoles, ventricular bigemini, couplets, or salvos) were associated with only a small proportion $(0 \%-5 \%)$ of episodes of transient ST depression on ambulatory monitoring. ${ }^{4513}$ Although by contrast, Gottlieb et al did find that ventricular extrasystoles were commoner after myocardial infarction in hours when transient myocardial ischaemia (mainly ST depression) occurred, the study population was a high risk subgroup with either severely impaired left ventricular function or high grade ventricular arrhythmias. ${ }^{14}$

It is possible that the degree of ischaemia is an important factor in determining whether arrhythmias will be triggered or not. Thus Maseri et al reported ventricular arrhythmias in 28 patients with angina at rest, most $(89 \%)$ of whom had ST elevation suggesting transmural ischaemia. ${ }^{6}$ Neither ourselves nor others, however, found any increase in ventricular arrhythmias during episodes of ST depression of greater depth or duration on ambulatory monitoring. ${ }^{13}$

Although ST depression was commoner during late than early ambulatory monitoring the lack of correlation found in this study between ambulatory ST depression and ventricular arrhythmias makes myocardial ischaemia an unlikely explanation for the increase in arrhythmias detected during late monitoring. It is possible though, that the increase in ventricular arrhythmias on late ambulatory monitoring may be related to an increase in heart rate, blood pressure, or catecholamine concentrations during increased physical activities out of hospital compared with convalescence before discharge. As fre- 
quent ventricular extrasystoles are associated with poor prognosis after myocardial infarction $^{15}$ the potentially large difference in the frequency of ventricular arrhythmias during these two recording periods should be taken into account if the results of ambulatory monitoring are used for prognostic stratification.

In our study there was no indication that silent myocardial ischaemia after myocardial infarction as indicated by ST depression on ambulatory monitoring was implicated in the genesis of ventricular arrhythmias. From these findings and the concordant information available from most other studies we do not think that a case can be made for attempting to abolish silent ischaemic ST depression on ambulatory monitoring after myocardial infarction to prevent ventricular arrhythmias.

We thank the British Heart Foundation and the Mersey Regional Health Authority for their financial support and the Cardiorespiratory Department and the Department of Cardiorespiratory Department and the Department of for technical assistance.

1 Sharma B, Asinger R, Francis GS, Hodges M, Wyeth RP. Demonstration of exercise-induced painless myocardial ischaemia in survivors of out-of-hospital ventricular fibrillation. Am f Cardiol 1987;59:740-5.

2 Salerno D, Hodges M, Graham E, Asinger RW, Mikell FL. Fatal cardiac arrest during continuous ambulatory monitoring [letter]. N Engl f Med 1981;305:700.

3 Deanfield JE, Selwyn AP, Chierchia S, et al. Myocardial ischaemia during daily life in patients with stable angina: its relation to symptoms and heart rate changes. Lancet 1983;1:753-8.

4 Mulcahy D, Keegan J, Crean P, et al. Silent myocardial ischaemia in chronic stable angina: a study of its frequency and characteristics in 150 patients. Br Heart $\mathcal{f}$ 1988;60:417-23.

5 Quyyumi AA, Crake T, Wright C, Mockus L, Levy RD, Fox KM. The incidence and morphology of ischaemic ventricular arrhythmias. Eur Heart $f$ 1986;7:1037-44.

6 Maseri A, Severi S, De Nes M, et al. "Variant" angina: one aspect of a continuous spectrum of vasospastic

7 Report of the Joint International Society and Federation of Cardiology and World Health Organization Task Force on Standardisation of Clinical Nomenclature. Nomenclature and criteria for diagnosis of ischemic heart disease. Circulation 1979;59:607-9.

8 Sibler S, Vogler AC, Spiegelsberger F, Vogel M, Theisen $\mathrm{K}$. Validation of digital Holter ST segment analysis. fournal of Ambulatory Monitoring 1988;1:145-52.

9 Quyyumi AA Crake T, Mockus LJ, Wright C, Rickards $\mathrm{AF}$, Fox KM. Value of the bipolar lead CM5 in electrocardiography. Br Heart $\mathcal{f} 1986 ; 56: 372-6$.

10 Currie P, Saltissi S. Transient myocardial ischaemia following acute myocardial infarction. Br Heart $\mathcal{F} 1990 ; 64$ : 299-303.

11 Quyyumi AA, Crake T, Wright C, Mockus L, Fox K. The role of ambulatory ST-segment monitoring in the diagnosis of coronary artery disease: comparison with exercise testing and thallium scintigraphy. Eur Heart $\mathcal{f} 1987$; 8:124-9.

12 Currie P, Saltissi S. Transient ischaemia after acute myocardial infarction: relationship to exercise ischaemia. Eur Heart f 1991;12:395-400.

13 Hausmann $D$, Nikutta $P$, Trappe HJ, Daniel WG, Wenzlaff $P$, Lichtlen $P R$. Incidence of ventricular arrhythmias during transient myocardial ischaemia in patients with stable coronary artery disease. $\mathfrak{F} \mathrm{Am}$ Coll Cardiol 1990;16:49-54.

14 Gottlieb SO, Gottlieb SH, Achuff SC, et al. Silent ischaemia on holter monitoring predicts mortality in ischaemia on holter monitoring predicts mortality in
high risk postinfarction patients. $\mathscr{A} A M A$ 1988;259: high risk

15 Bigger JT Jr, Fleiss JL, Kleiger R, Miller JP, Rolnitzky LM, The Multi Center Post-Infarction Research Group. The relationships among ventricular arrhythmias, left ventricular dysfunction, and mortality in the 2 years after myocardial infarction. Circulation 1984;69: $250-8$. 